Chapter 15

\title{
The HIV-1 Integrase: Modeling and Beyond
}

\author{
Rohit Arora and Luba Tchertanov \\ Additional information is available at the end of the chapter \\ http://dx.doi.org/10.5772/52344
}

\section{Introduction}

Molecular recognition is a fundamental phenomenon observed in all biological systems organisation - proteins, nucleic acids and their complexes, cells and tissues. Molecular recognition is governed by specific attractive interactions between two or more partner molecules through non-covalent bonding such as hydrogen bonds, metal coordination, electrostatic effects, hydrophobic and van der Waals interactions. The partners - receptor(s) and substrate(s) or ligands - involved in molecular recognition, exhibit molecular complementarity that can be adjusted over the recognition process. Competition and cooperation, the two opposite natural effects contributing to selective and specific recognition between participating partners, are the basic principles of substrate/ligand/inhibitor or protein binding to its targets.

The tertiary structures of biological objects (proteins and nucleic acids) are formed mainly by hydrogen bonds (enthalpic contributions) and by hydrophobic contacts (mostly entropic contributions). With a few exceptions, (e.g. ligand binding to the Ah receptor), the organisation of ligand-protein complexes depends primarily on hydrogen bonding.

In the process of a ligand binding to its target the hydrogen bonds contribute to (i) the orientation of the substrates/ligands/inhibitors by a receptor, frequently associated with a conformational/structural adjustment of the interacting agents; (ii) the specific recognition of substrates/ligands/inhibitors and selectivity between sterically or structurally similar but biochemically different species; (iii) the affinity of ligands/inhibitors - the most decisive factor in drug design.

To describe the pharmacological properties of a given ligand or inhibitor, the knowledge of the site where the inhibitor is to bind with the target and of which interaction(s) control the specific recognition of the inhibitor by its target(s), represents a corner stone factor. Only a limited number of target-ligand molecular complexes have been characterized experimen- 
tally at the atomic level (X-ray or NMR analysis) [1]. Part of them describes the binding mode of therapeutically relevant ligands to biologically non-relevant and non-pertinent targets (e.g., the HIV-1 integrase specific inhibitor RAL was published as a ligand fixed to the PFV intasome [2,3]). Consequently, a large quantity of reliable information on target-ligand binding is based on molecular docking methods which generate insights into the interactions of ligands with the amino acid residues in the binding pockets of the targets, and also predict the corresponding binding affinities of ligands [4]. The first step of a docking calculation consists of the choice or generation/construction of the therapeutically appropriate target. Frequently the target modeling is a hard computational task which requires the application of sophisticated theoretical methods and constitutes a fascinating creative process.

Therefore, theoretical studies contribute first, to establish biologically valid models of the targets; second, through the use of these models, to the understanding of the protein functional properties; and finally to apply this data to rational drug design.

Here we compile and review the data on the molecular structure, properties and interactions of the HIV-1 integrase representing from one side, a characteristic example of a polyfunctional and complex biological object interacting with different viral and cellular partners and from another side, an attractive therapeutical target. We attempt to extract key messages of practical value and complement references with our own research of this viral enzyme. We characterized the structural and conformational features of Raltegravir (RAL), the first integrase specific inhibitor approved for the treatment of HIV/AIDS, and we analyzed the factors contributing to RAL recognition by the viral targets.

\section{The HIV-1 integrase and integrase-viral DNA pre-integration complex}

\subsection{Activities}

The HIV-1 integrase (IN) is a key enzyme in the replication mechanism of retroviruses, catalyzing the covalent insertion of the reverse-transcribed DNA into the chromosomes of the infected cells [5]. Once integrated, the provirus persists in the host cell and serves as a template for the transcription of viral genes and replication of the viral genome, leading to production of new viruses (Figure 1a). A two-step reaction is required for covalent integration of viral DNA (vDNA) into host DNA (hDNA). First, IN binds to a short sequence located at either end of the long terminal repeat (LTR) of the viral DNA and catalyzes an endo-nucleotide cleavage. This process is known as $3^{\prime}$-processing reaction $\left(3^{\prime}-\mathrm{P}\right)$, resulting in the removal of two nucleotides from each of the 3 '-ends of the LTR and the delivery of hydroxyl groups for nucleophilic attacks (Figure $1 \mathrm{~b}$ ).

The cleaved (pre-processed) DNA is then used as a substrate for the strand transfer (ST) reaction, leading to the covalent insertion of the vDNA into genome of the infected cell $[5,7]$. The ST reaction occurs at both ends of the vDNA simultaneously, with an offset of precisely five base pairs between the two distant points of insertion. The integration process is accomplished by the removal of unpaired dinucleotides from the $5^{\prime}$-ends of the vDNA, the filling 
in of the single-strand gaps between viral and target DNA molecules and ligation of the 3'ends of the vDNA to the $5^{\prime}$-ends of the hDNA (Figure $1 \mathrm{~b}$ ). These two reactions are spatially and temporally separated and energetically independent: the $3^{\prime}$-processing takes place in the cytoplasm of the infected cells, whereas strand transfer occurs in the nuclei. They are catalyzed by the enzyme in different conformational and oligomerisation states: dimerization is required for the 3'-processing step [8,9], while tetrameric IN is believed to be required for strand transfer [10-12].

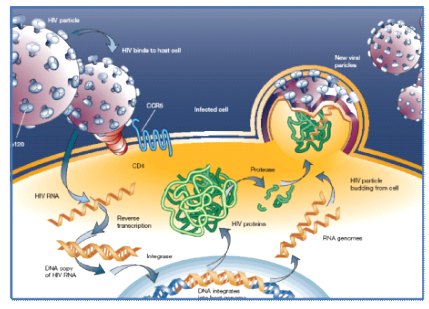

(a)

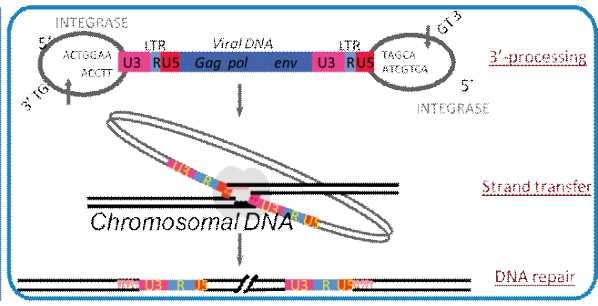

(b)

Figure 1. The HIV-1 replication cycle (a) and catalytic steps involved in the insertion of viral DNA into the human genome (b) [6].

\subsection{Structural data}

The HIV-1 IN is a 288 amino acids enzyme (32 kDa) that consists in three structurally distinct domains: (i) the N-terminal domain $\left(\mathrm{NTD}, \mathrm{IN}^{1-49}\right)$ with a non-conventional HHCC zincfinger motif, promoting protein multimerization; (ii) the central core domain (CCD, $\mathrm{IN}^{50-212}$ ) containing a canonical D,D,E motif performing catalysis and involved in DNA substrate recognition [35]; (iii) the C-terminal domain (CTD, IN ${ }^{213-288}$ ), which non-specifically binds DNA and helps to stabilize the IN•vDNA complex [13]. Both integration steps, $3^{\prime}-\mathrm{P}$ and ST, involve the active site and the active site flexible loop formed by ten residues, IN ${ }^{140-149}$.

Neither the structure of isolated full-length IN from HIV-1 nor that of IN complex with its DNA substrate has been determined. Nevertheless, the structures of the isolated HIV-1 domains or two domains were characterized by X-ray crystallography (34 structures) and NMR analysis (9 structures) [1]. NTD presented by 6 NMR structure solutions (1WJA, 1WJB, 1WJC, 1WJE, and 1WGF) [14-16] was classified by SCOP as the 'all alpha helix' structure and consists of four helices stabilized by a $\mathrm{Zn}^{2+}$ cation coordinated with the HHCC motif (His12, His16, Cys40 and Cys43); the sequence from 43 to 49 residue are disordered (Figure 2). Structure of CTD was also characterised by NMR (3 deposited solutions (1IHV, 1IHW and $1 \mathrm{QMC})[17,18]$. According to the SCOP classification it presents the 'all beta strand' structure and consists of five anti-parallel $\beta$-strands forming a $\beta$-barrel and adopting an SH3-like fold (Figure 2). 
The human IN CCD characterized by X-ray analysis has been reported as 14 different crystal structures (1HYV, 1HYZ, 1EXQ, 1QS4, 1B92, 1B9D, 1BHL, 1BI4, 1BIS, 1BIU, 1BIZ, 1BL3, 1ITG and 2ITG). The wild-type IN was resolved with a poor precision (1ITG) [19], the other structures represent engineered mutants, either single $(\mathrm{F} 185 \mathrm{~K} / \mathrm{H})$ [20-23], double (W131E and F185K; G149A and F185K or C56S and F185K) [24-26] or multiple (C56S, W131D, F139D and F185K) [27] mutants which were designed to overcome the poor solubility of the protein. The core domain has a mixed $\alpha / \beta$ structure, with five $\beta$-sheets and six $\alpha$-helices (Figure 2).

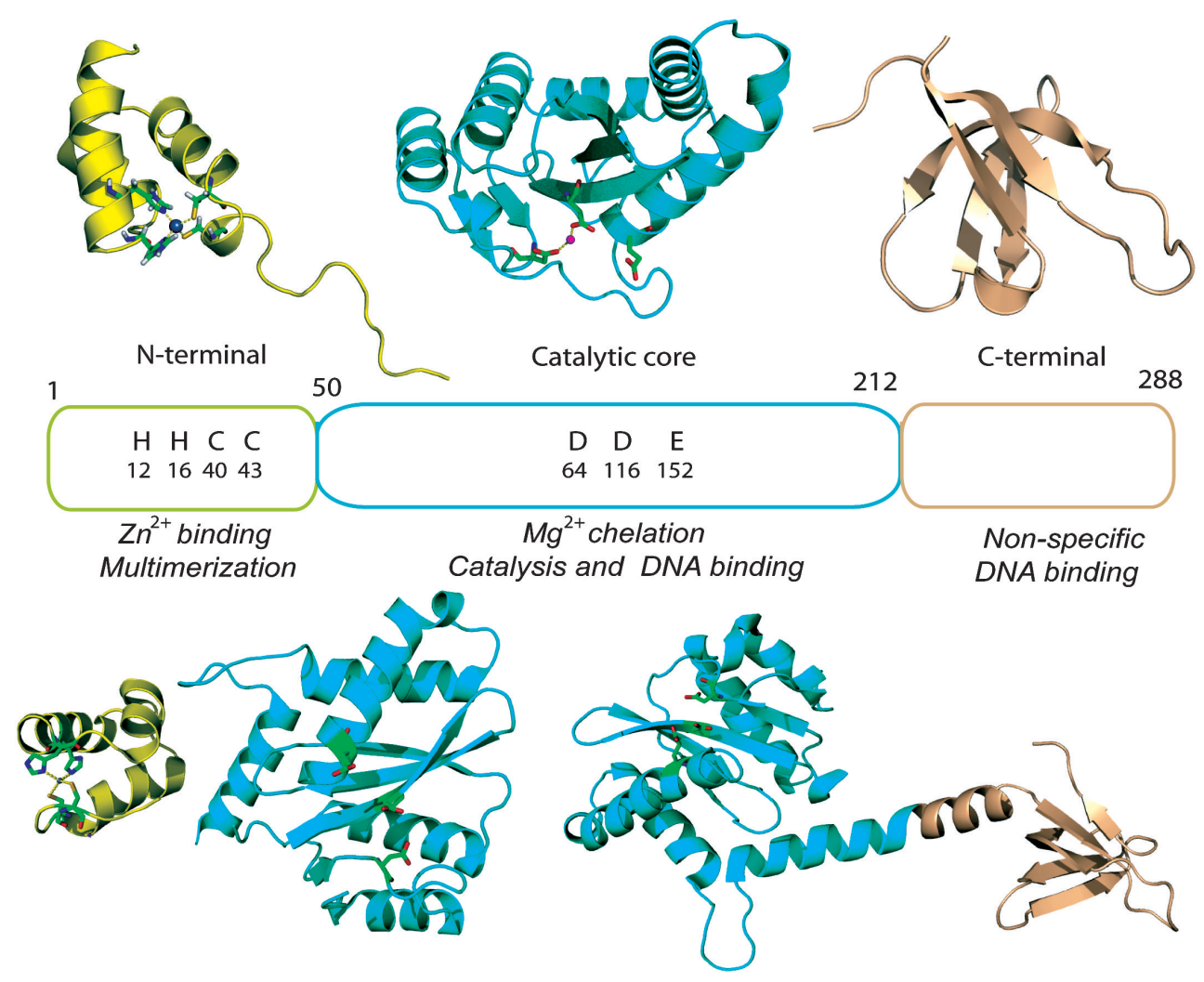

Figure 2. Structural domains of the HIV-1 integrase. (Top) N-terminal (IN ${ }^{1-49}$, left), catalytic core (IN ${ }^{50-212}$, middle) and C-terminal (IN219-270, right) domains; (bottom) N-terminal with catalytic core domain (IN ${ }^{1-212}$, left) and catalytic core with C-terminal fragment (IN $\mathrm{N}^{52-288}$, right). The structures are shown as cartoon with the side chains of the HHCC and DDE motifs in the $\mathrm{N}$-terminal and catalytic core domains rendered in stick and the $\mathrm{Zn}^{2+}$ and $\mathrm{Mg}^{2+}$ cations as balls; dashed lines indicate ion coordination $[28,29]$.

The active site residues D64, D116 and E152 are located in different structural elements: $\beta$ sheet $(\beta 1)$, coil and helix $(\alpha 4)$, respectively. The catalytic core domain also encompasses a 
flexible loop comprising residues 140-149, in which conformational changes are required for $3^{\prime}$-P and ST reactions. These activities require the presence of a metallic cofactor(s), the $\mathrm{Mg}^{2+}$ ion(s), which binds to the catalytic residues D64, D116 and E152. The number of $\mathrm{Mg}^{2+}$ cations is different for the distinct enzymatic reactions and consequently, for the different IN states: a single $\mathrm{Mg}^{2+}$ cation in non-processed IN, and two in processed IN. The structures of avian sarcoma virus (ASV) IN [21] and the Tn5 transposase[30] have provided evidence of a two-metal active site structure, which has been used to build metal-containing IN models [31-33].

Crystallographic structures of $\mathrm{IN}^{1-212}$ and $\mathrm{IN}^{50-288}$ two-domain constructs have also been obtained for W131D/F139D/F185K and C56S/W131D/F139D/F185K/C180S mutants, respectively (Figure 2) [34,35]. In the first of these structures, there is an asymmetric unit containing four molecules forming pairs of dimers connected by a non-crystallographic two fold axis, in which the catalytic core and N-terminal domains are well resolved, their structures closely matching those found with isolated $\mathrm{IN}^{1-45}$ and $\mathrm{IN}^{50-212}$ domains, and connected by a highly disordered linking region (47-55 amino acids). The X-ray structure of the other two-domain construct, $\mathrm{IN}^{50-288}$, showed there was a two-fold symmetric dimer in the crystal. The catalytic core and C-terminal domains were connected by a perfect helix formed by residues 195-221. The local structure of each domain was similar to the structure of the isolated domains. The dimer core domain interface was found to be similar to the isolated core domain, whereas the dimer C-terminal interface differed from that obtained by NMR.

\subsection{Theoretical models}

All these structural data characterising the HIV-1 IN single or two-domains allow the generation of biologically relevant models, representing either the unbound dimeric enzyme or IN complexed with the viral or/and host DNA [29].

IN acts as a multimer [36]. Dimerization is required for the $3^{\prime}$-processing step, with tetrameric IN catalyzing the ST reaction $[37,38]$. Dimeric models were built to reproduce the specific contacts between IN and the LTR terminal CA/TG nucleotides identified in vitro [39,40]. However, most models include a tetrameric IN alone or IN complex with either vDNA alone or vDNA/hDNA, recapitulating the simultaneous binding of IN to both DNAs required for strand transfer (Figure $3 \mathrm{~b}-\mathrm{d}$ ).

These models were either based on the partial crystal structure of IN [32,44] or constructed by analogy with a synaptic Tn5 transposase complex described in previous studies $[42,45,46]$.

Most models include an $\mathrm{Mg}^{2+}$ cationic cofactor and take into account both structural data and biologically significant constraints (Figure $2 \mathrm{~b}-\mathrm{d}$ ). In particular, HIV-1 IN synaptic complexes (IN •vDNA $\bullet$ hDNA) have been constructed taken into account the different enzymatic states occurring during the integration process (Figure $3 \mathrm{~d}$ ) [41,42]. Such complexes have also been characterized by electron microscopy (EM) and single-particle imaging at a resolution of $27 \AA$ [47]. Recently the X-ray complete structure of the Primate Foamy Virus (PFV) 
integrase in complex with the substrate DNA and Raltegravir or Elvitegravir has also recently been reported (Figure 3 e) [2].

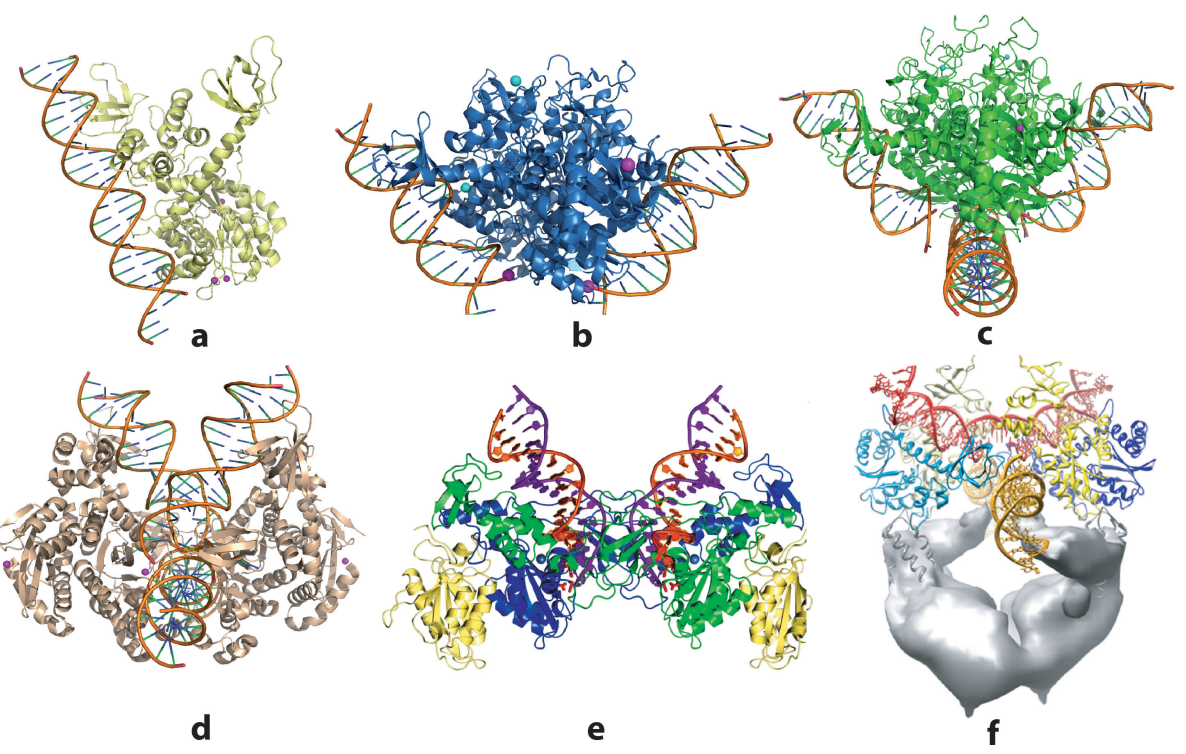

Figure 3. Integrase architecture and organization. Theoretical models: (a) dimeric model of the full-length IN•vDNA-

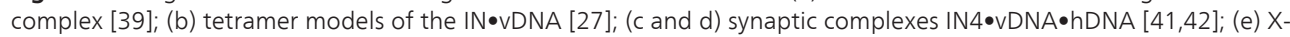

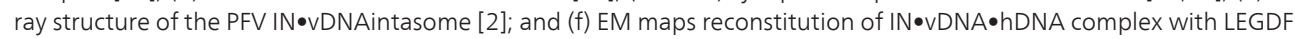
[43]. Protein and DNA structures are presented as cartoon with colour coded nucleotides and $\mathrm{Zn}^{2+}$ and $\mathrm{Mg}^{2+} \mathrm{cations}$ shown as balls. The active site contains two $\mathrm{Mg}^{2+}$ cations in (a) and one in (b-d).

In this complex, the retroviral intasome consists of an IN tetramer tightly associated with a pair of viral DNA ends. The overall shape of the complex is consistent with a low-resolution structure obtained by electron microscopy and single-particle reconstruction for HIV-1 IN complex with its cellular cofactor, the lens epithelium-derived growth factor (LEDGF) (Figure 3 d) [43].

\subsection{Targets models representing the HIV-1 integrase before and after 3 '-processing}

Recently new HIV-1 IN models were generated by homology modeling. They represent with a certain level of reliability two different enzymatic states of the HIV-1 IN that can be explored as the biological relevant targets for design of the HIV-1 integrase inhibitors (Figure 4). The generated models are based on the experimental data characterising either the partial structures of IN from HIV-1 or full-length IN from PFV. The models of the separated full-length HIV-1 integrase represent the unbound homodimers of IN (IN1-270) containing either one or two $\mathrm{Mg}^{2+}$ cations in the active site - a plausible enzymatic state before the $3^{\prime}$ 
processing. The catalytic site loop encompassing ten residues forms the boundary of the active site. This loop shows either a coiled structure $[20,22,24]$ or contains an $\Omega$-shaped hairpin $[28,48]$.

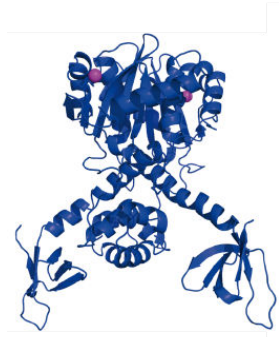

a

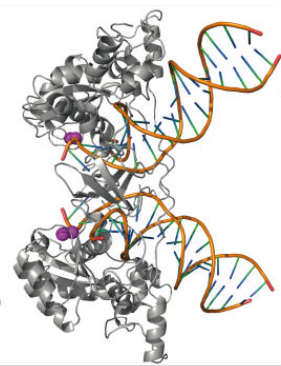

b
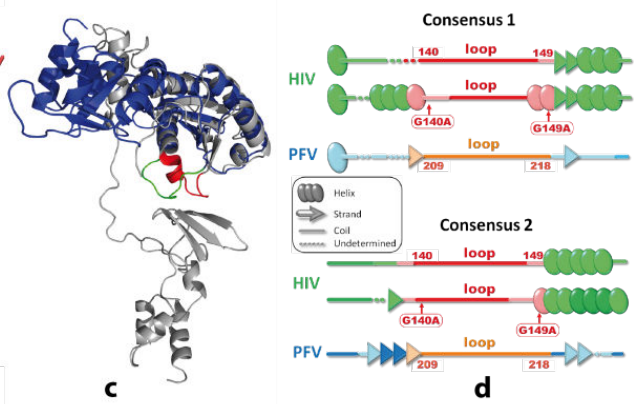

Figure 4. Structural models of the HIV-1 integrase. (a) Model of unbound IN representing the homodimeric enzyme before the 3'-processing; (b) Model of the simplified (dimeric form) IN•DNA pre-integration complex; (c) Superimposition of monomeric subunits from two models in which catalytic site loop residues 140-149 are shown by colours (red and green).The proteins are shown as cartoons, $\mathrm{Mg}^{2+}$ ions as spheres (in magenta). (d) Schematic representation of the HIV and PVF active site loop secondary structure prediction, according to consensus 1 and consensus 2 .

It will be useful to note that we evidenced a high flexibility of the functional domains in unbound IN by using the Normal Modes Analysis (NMA) [49,50]. Particularly, CTD is characterized by a large scissors-like movement (Figure 5 a). We established that the catalytic site loop in unbound IN with two $\mathrm{Mg}^{2+}$ cations in the active site is more rigid due to the stabilising role of the coordination of the $\mathrm{Mg}^{2+}$ cations by three active site residues, D64, D116 and E152, whereas the catalytic site loop flexibility increases significantly (Figure 5 b, c).
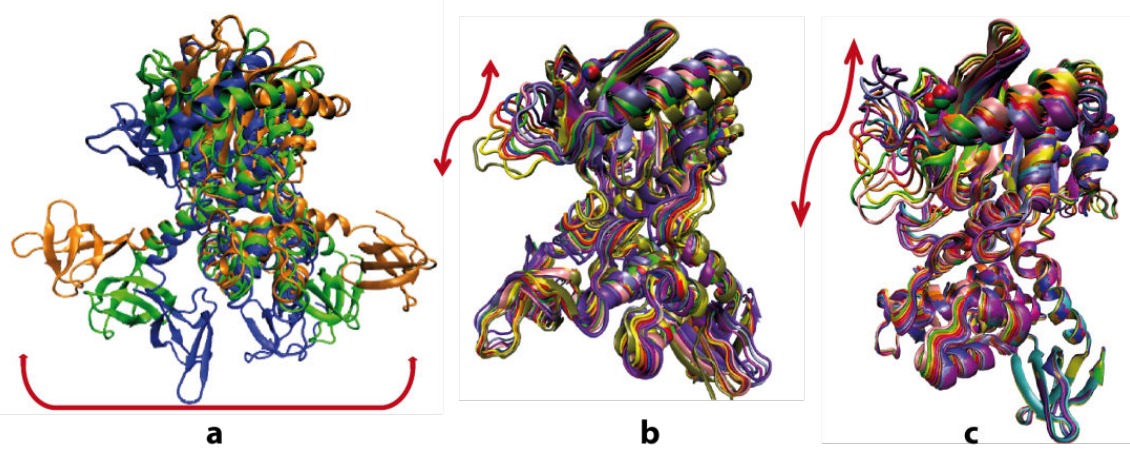

Figure 5. Normal modes illustrating fragments movement in unbound IN. A scissors-like movement in CTD (a); the catalytic site loop displacement in unbound IN with one and two $\mathrm{Mg}^{2+}$ cation(s) in the active site (b) and (c) respectively (S. Abdel-Azeim, personal communication). 
The simplified model of the HIV-1 IN •vDNA pre-integration complex represents the homodimer of integrase non-covalently attached to the two double strains of the viral DNA with two removed nucleotides GT at each 3'-end (Figure 4 b), and likely depicts the biologically active unit of the IN $\bullet$ vDNA strand transfer intasome. The IN $\bullet$ vDNA model was generated from the X-ray structure of the PFV intasome [2]. Despite the very low sequence identity (22\%) between the HIV-1 and PFV INs, the structure-based alignment of the two proteins demonstrates high conservation of key secondary structural elements and the three PFV IN domains shared with HIV-1 IN have essentially the same structure as the isolated IN domains from HIV-1 [51]. Moreover, the structure of the PFV intasome displays a distance between the reactive $3^{\prime}$ ends of vDNA that corresponds to the expected distance between the integration sites of HIV-1 IN target DNA (4 base pairs). Consequently, we suggested that the PFV IN X-ray structure represents an acceptable template for the HIV-1 IN model generation [52].

Two models of different states of the HIV-1 IN show a strong dissimilarity of their structure evidenced by divergent relative spatial positions of their structural domains, NTD, CCD and CTD (Figure $4 \mathrm{c}$ ). These tertiary structural modifications altered the contacts between IN domains and the structure and conformation of the linker regions. Particularly, the NTD-CCD interface exhibits substantial changes: in the unbound form the NTD-CCD interface belongs to the same monomer subunit whereas in the vDNA-bound form the interface is composed of residues from the two different subunits. Moreover, IN undergoes important structural transformation leading to structural re-organisation of the catalytic site loop; the coiled portion of the loop reduces from ten residues in the unbound form to five residues in the vDNA-bound form. Such effect may be induced either by the vDNA binding or it can derive as an artefact produced from the use of structural data of the PFV IN as a template for the model generation. Prediction of $\mathrm{IN}^{133-155}$ sequence secondary structure elements indicates a more significant predisposition of IN from HIV-1 to be folded as two helices linked by a coiled loop than the IN from PFV (Figure $4 \mathrm{~d}$ ). Prediction results obtained with high reliability $(>75 \%)$ correlate perfectly with the X-ray data characterising the WT HIV-1 integrase (1B3L) [22] and its double mutant G140A/G149A (1B9F) [26]. The helix elongation accompanied by loop shortening may be easily induced by the enzyme conformational/structural transition between the two integration steps prompted by substrate binding.

This structure can be used to generate reliable HIV-1 IN models for Integrase Strand Transfer Inhibitors (INSTIs) design. However, the active site loop adopts a five-residue coil structure, rather than the ten-residue extended loop observed in HIV-1IN. This difference may be due to a difference in the sequence of the two enzymes or an effect induced by DNA binding, and caution is therefore required in the use of this structure as a template for modelling biologically relevant conformations of HIV-1 IN [2,45].

\subsection{Transition pathway between two IN states and the allosteric binding sites}

Two different states of the HIV-1 IN represent the enzyme structures before and after 3'processing. Under integration process, IN as many other proteins undergo large conformational transitions that are essential for its functions (Figure 6) [53-55]. Tertiary structural 
changes precede and accompany these quaternary transitions in the HIV-1 IN as was evidenced by Targeted Molecular Dynamics (TMD) [56] and Meta Dynamics (MD) [57] (Figure $6 \mathrm{c}, \mathrm{d})$.

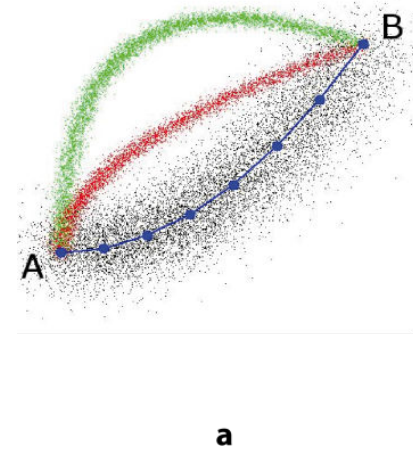

a

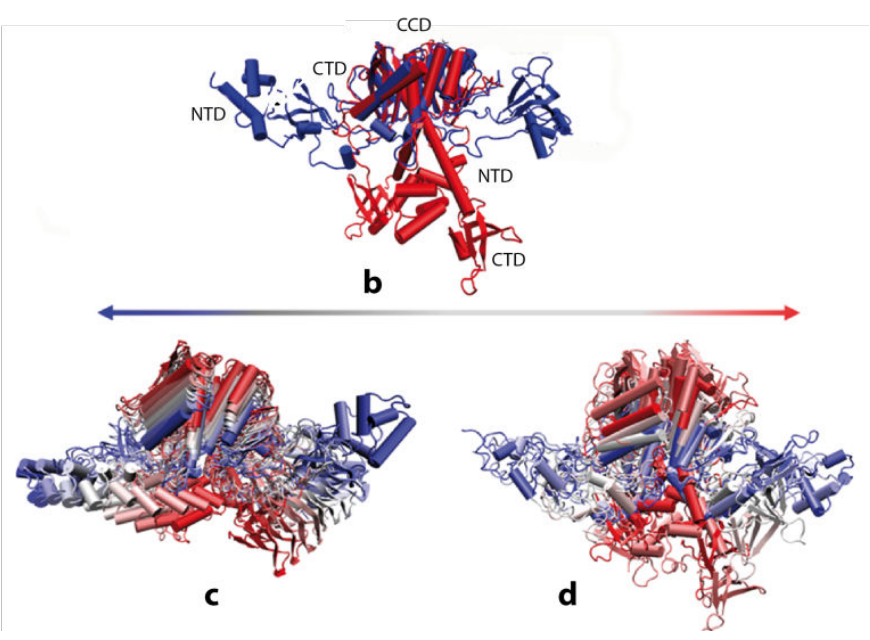

Figure 6. Transition states ensemble between A and B structures (a) (A. Blondel, personal communication). A series of conformations visited by the HIV-1 IN over transition from unbound IN to IN•vDNA complex before (red) and after (blue) 3'-processing (b) obtained by Targeted Molecular Dynamics (TMD) (c) and Meta Dynamics (MD) simulations (d) (S. Abdel-Azeim, personal communication).

Our results, first, provide a description of structure-dynamics-function relationships which in turn supplies a plausible understanding of the IN 3'-processing at the atomic level. Second, the calculated intermediate conformations along the trajectories were scanned for molecular pockets - a means of exploring putative allosteric binding sites, particularly positioned on the IN C-terminal domain (CTD), which is responsible for the vDNA recognition (Figure 7).

\section{Raltegravir}

The integrase inhibitors were developed to block either the 3'-processing or the strand transfer reaction [58-60]. Raltegravir (RAL), the first IN inhibitor approved for AIDS treatment [61] specifically inhibits the ST activity and was confirmed as an integrase ST inhibitor (INSTI), whereas the $3^{\prime}-\mathrm{P}$ activity was inhibited only up to a certain concentration $[28,62]$. The potency of RAL has been described at the level of half-maximal inhibitory concentration (IC50 values) in cellular antiviral and recombinant enzyme assays, kinetic analysis and slow-binding inhibition of IN-catalyzed ST reaction [62-68]. Particularly, it has an $\mathrm{IC}_{50}$ of 2 to $7 \mathrm{nM}$ for the inhibition of recombinant IN-mediated ST in vitro and an $\mathrm{IC}_{95}$ of 19 and $31 \mathrm{nM}$ in 10\% FBS (fetal bovine serum) and $50 \%$ NHS (normal human serum), respectively. This 
drug has been reported to be approximately 100-fold less specific for the inhibition of 3'processing activity compared to strand transfer. The dissociation rate of RAL with $\mathrm{IN} \bullet \mathrm{vDNA}$ complex was slow, with $k_{\text {off }}$ values of $(22 \pm 2) \times 10^{-6} \mathrm{~s}^{-1}$. The dissociative half-life value measured for RAL with the wild type IN•vDNA complex was $7.3 \mathrm{~h}$ and $11.0 \mathrm{~h}$ obtained at $37^{\circ} \mathrm{C}$ and at $25^{\circ} \mathrm{C}$ respectively.

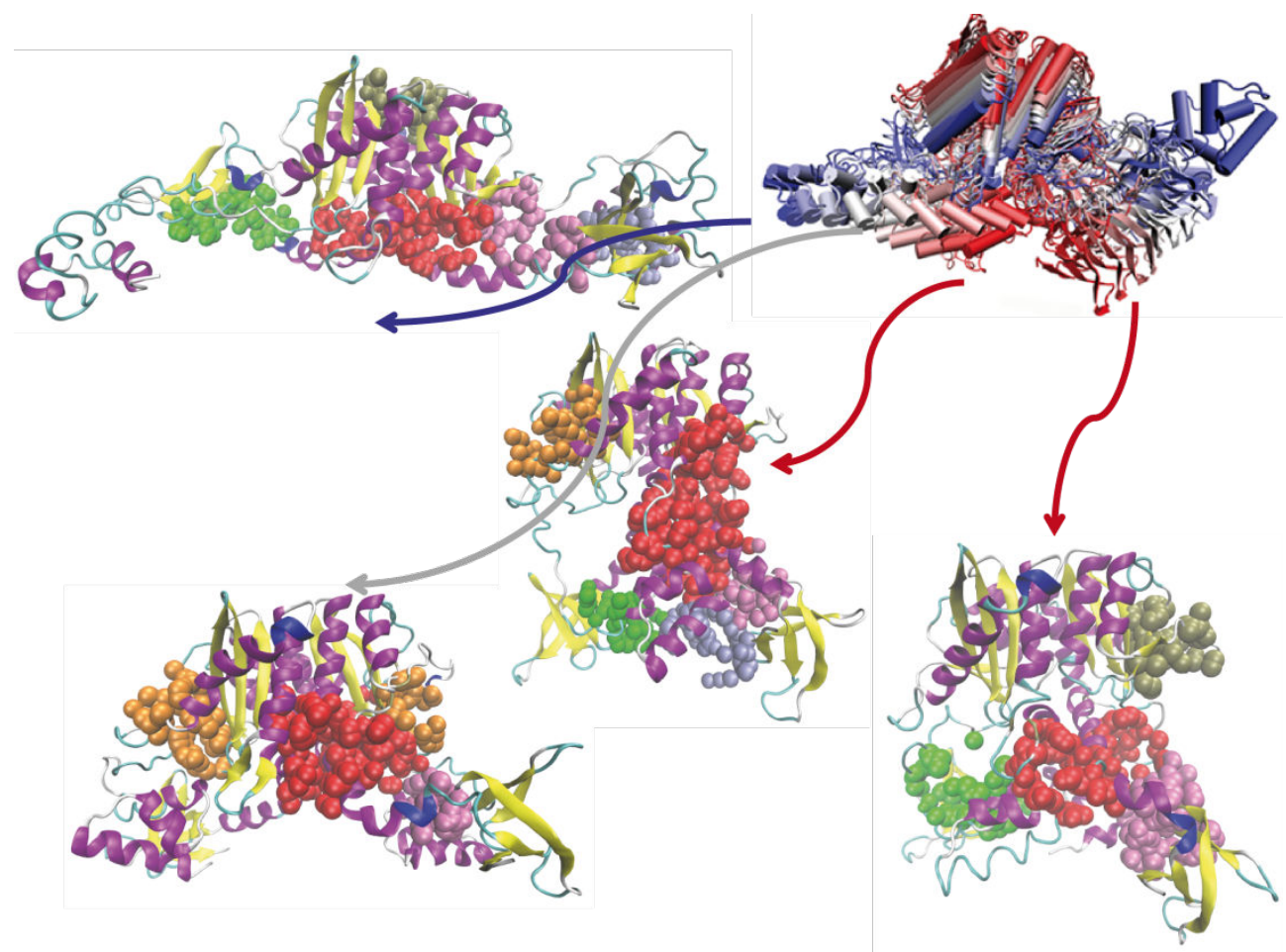

Figure 7. Pockets detected on the surface of the HIV-1 Integrase intermediate conformations obtained by Targeted Molecular Dynamics (TMD) simulations. (S. Abdel-Azeim, personal communication).

Like other antiretroviral inhibitors, RAL develops/induces a resistance effect. Resistance to RAL was associated with amino acids substitutions following three distinct genetic pathways that involve either $\mathrm{N} 155 \mathrm{H}$, either Q148R/K/H or Y143R primary mutation $[69,70]$. The last mutation was reported as rare [71]. It was supposed that the integrase active site mutation $\mathrm{N} 155 \mathrm{H}$ causes resistance to raltegravir primarily by perturbing the arrangement of the active site $\mathrm{Mg}^{2+}$ ions and not by affecting the affinity of the metals or the direct contacts of the inhibitor with the enzyme [72].

G140S has been shown to enhance the RAL resistance associated with Q148R/K/H [73]. The kinetic gating and/or induced fit effect have been reported as possible mechanisms for RAL 
resistance of the G140S/Q148H mutant [74]. A third pathway involving the Y143R/C/H mutation and conferring a large decrease in susceptibility to RAL has been described [75].

\subsection{Structure and conformational flexibility}

No experimental data characterizing RAL unbound structure or RAL binding mode to the HIV-1 IN has been reported. In this regard, the characterization of RAL conformational preferences and the study of its binding to the HIV-1 IN represent an important task for determining the molecular factors that contribute to the pharmacological action of this drug. Crystallographic data describing the separate domains of the HIV-1 IN and the full-length PFV IN with its cognate DNA deposited in the PDB, provide useful experimental starting guide for the theoretical modeling of the structurally unstudied objects, IN and IN•vDNA complex of HIV-1 as the RAL targets.

RAL, incorporating two pharmacophores, is a multipotent agent capable to hit more than one target in HIV-1, the unbound IN, the viral DNA or IN•vDNA complex. RAL shows the configurational $\mathrm{E} / \mathrm{Z}$ isomerism and a high conformational flexibility due to eight aliphatic single bonds. Two pharmacophores, (1) 1,3,4-oxadiazole-2-carboxamide and (2) carbonylamino-1-N-alkyl-5-hydroxypyrimidinone, possessing structural versatility through the orientation of carboxamide fragments respective to the aromatic rings, show E-, Z-configuration states characterizing the relative position of the vicinal 1-4 and 1-5 oxygen atoms [48] (Chart 1). The molecule has a set of multiple H-bond donor and acceptor centres. These molecular features together with high structural flexibility provide an abundance of alternative monoand bi-dentate binding sites in a given RAL conformation.
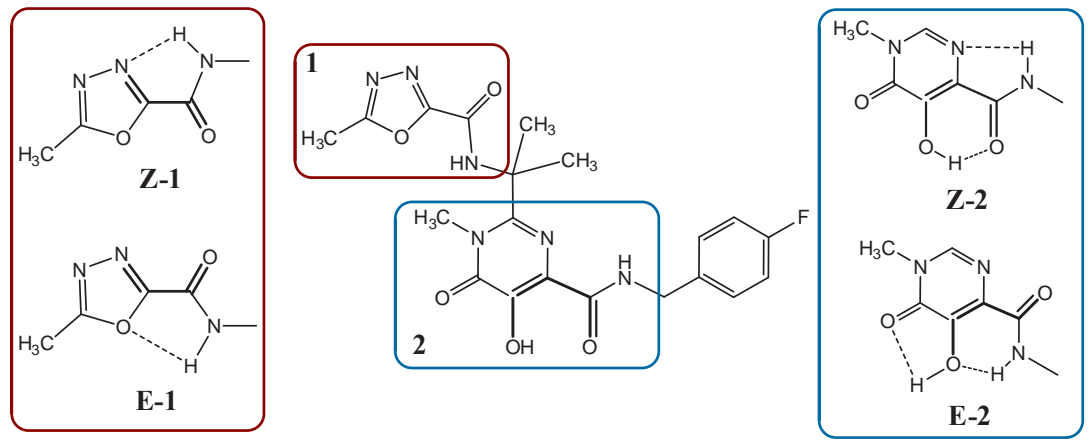

Chart 1. RAL structure. The E- and Z-isomers of 1,3,4-oxadiazole-2-carboxamide (1) and carbonylamino-1-N-alkyl-5hydroxypyrimidinone (2) pharmacophores are stabilized by intramolecular $\mathrm{H}$-bonds.

The chelating properties of protonated or deprotonated RAL are also determined by the Eor Z- configuration (Chart 2). Consequently, RAL can contribute in the recognition and binding of different partners - H-donor, $\mathrm{H}$-acceptors, charged non-metal atoms and metal cations - in topologically distinct regions of IN by applying the richness of its molecular and 
structural properties. For instance, RAL as a bioisoster of adenine can block IN interaction with DNA [48] or sequester metal cofactor ions [76].<smiles>CNC(=O)c1cc(=O)n(C)cc1OO</smiles>

1-a

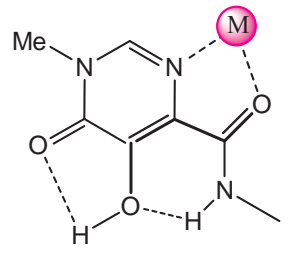

2-b<smiles></smiles>

1-b<smiles></smiles>

2-c

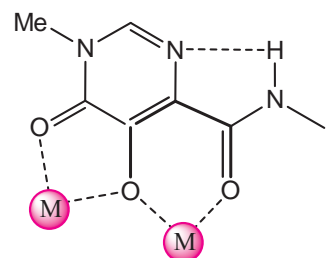

2-a<smiles></smiles>

2-d

Chart 2. Metal chelating properties of 1,3,4-oxadiazole-2-carboxamide (1) and carbonylamino-1-N-alkyl-5-hydroxypyrimidinone (2) moieties.

The conformational preferences of RAL were examined in the gas phase (conformational analysis), in water solution (molecular dynamics, MD, in explicit solvent) and in the solid state (the fragment-based analysis using the crystallographic data from Cambridge Structural Database, CSD [77]. Conformational analysis of the different isomeric states of RAL in the gas phase indicates a small difference between the energy profiles of the Z-1/Z-2 and E-1/Z-2 isomers suggesting a relatively low energetical barrier between these two inhibitor states (Figure 8).

A slight preference for the Z-configuration of carbonylamino-hydroxypyrimidinonepharmacophore in the gas phase was observed, in coherence with the established predisposition of $\beta$-ketoenols - a principle corner stone of this pharmacophore - to adopt the Z-isomer in the solid state (Figure $9 \mathrm{~b}$ ) [78-80]. The preference of aliphatic $\beta$-ketoenols to form energetically favorable Z-configurartion has been predicted early by ab initio studies at the B3LYP/3-G** level of theory [81].

The Cambridge Structural Databank search (CSD) [77] based on molecular fragments mimicking the RAL pharmacophores statistically demonstrates the preferential E-configuration of oxadiazolecarboxamide-like molecules and the Z-configuration of carbonylamino-hydroxypyrimidinone-like molecules in the solid state (Figure 9 a and b respectively). The halogenated aromatic rings, widely used pharmacophores, show a great level of conformational flexibility (Figure 9, c), allowing to contribute to a better inhibitor affinity in the binding site. 

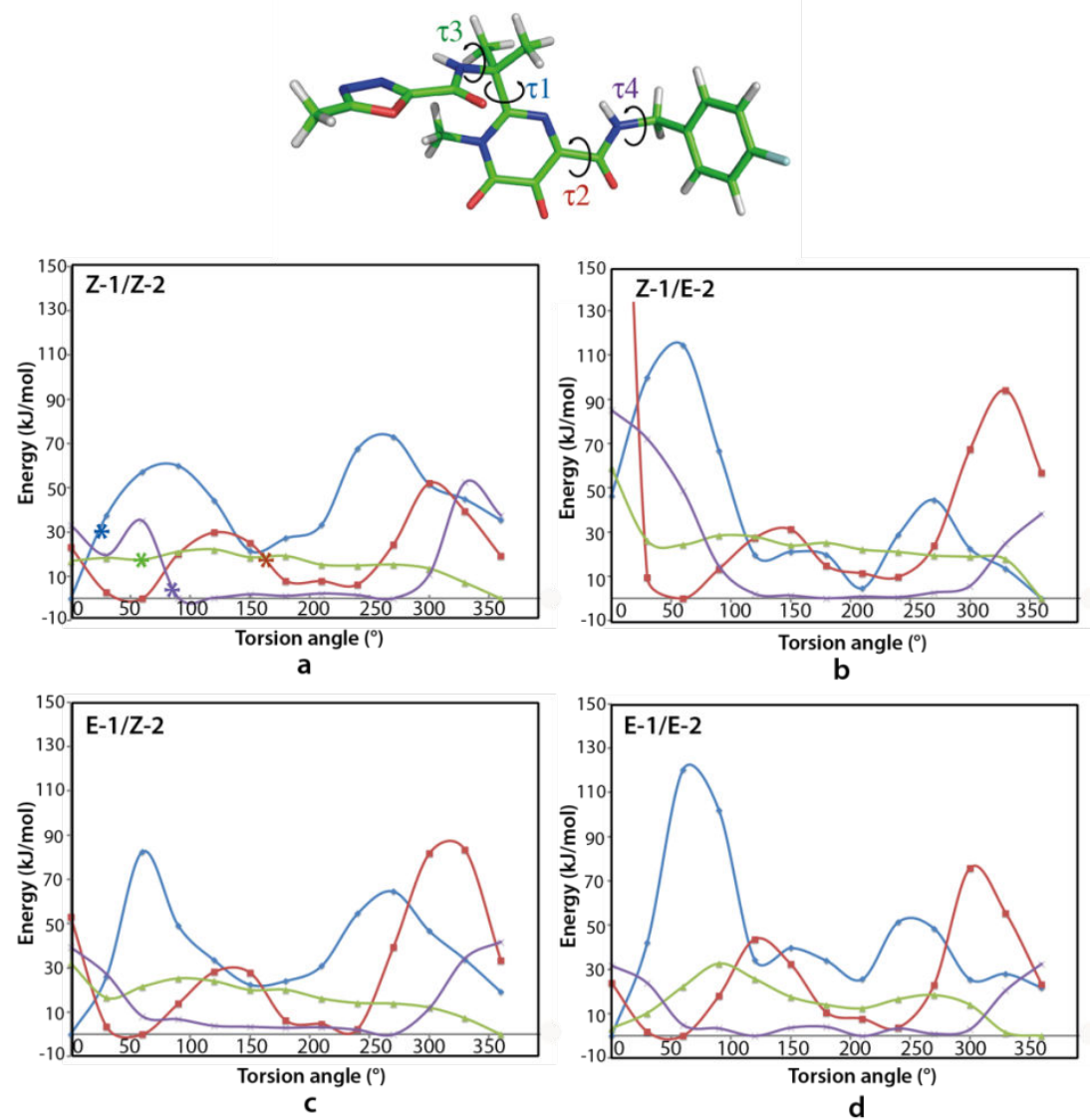

Figure 8. RAL conformations in the gas phase. Free energy profiles obtained by relaxed scans around the single bonds of RAL from 0 to $360^{\circ}$ with an increment step of $30^{\circ}$, considering the four RAL isomers: (a) Z-1/Z-2, (b) Z-1/E-2, (c) $\mathrm{E}-1 / \mathrm{Z}-2$ and $(\mathrm{d}) \mathrm{E}-1 / \mathrm{E}-2$. The curves representing the rotations around torsion angles $\tau 1, \tau 2, \tau 3$ and $\tau 4$ are shown in blue, red, green and violet colours. The values of $\tau 1, \tau 2, \tau 3$ and $\tau 4$ observed in RAL crystal structure $30 Y A$ are indicated by asterisks.

\subsection{Raltegravir-metal recognition}

Synthesized as a metal cations chelating ligand, RAL can bind the metal by both pharmacophores in different isomerisation states. Probing the RAL chelating features with relevant cations, $\mathrm{K}, \mathrm{Mg}$ and $\mathrm{Mn}$, we evidenced that in the majority of metal complexes, the carbonylaminohydroxypyrimidinone-like fragments are observed in the $\mathrm{Z}$ configuration in the solid state (Figure 10). 


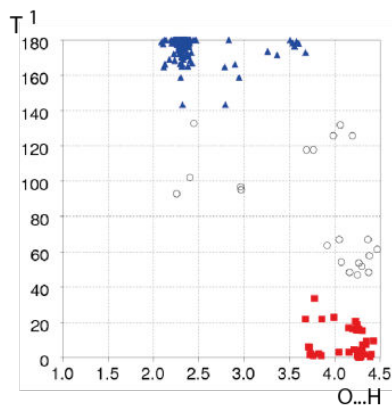

a

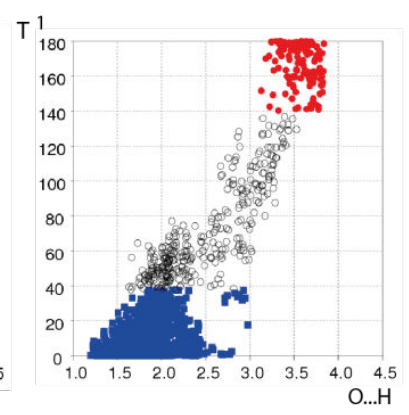

b

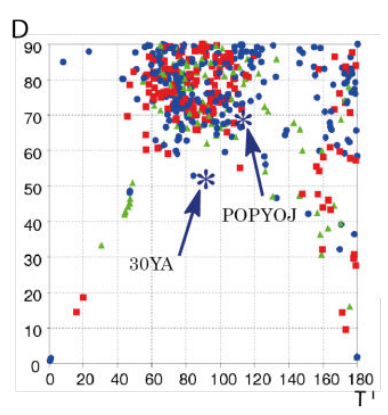

C
GACMUT

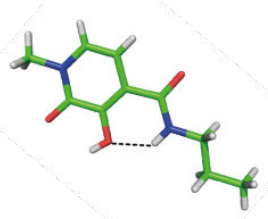

d

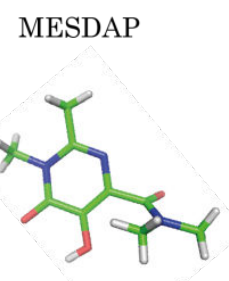

e
POPYOJ

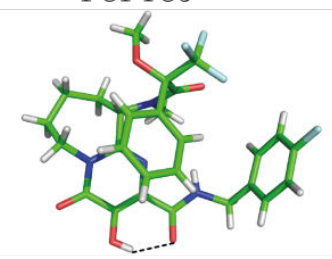

$f$
30YA

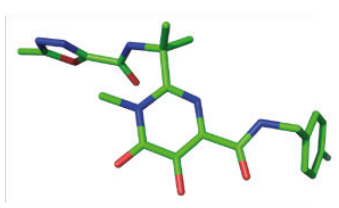

g

Figure 9. RAL conformations in the solid state. CSD fragment-based analysis of the RAL subunits indicates the E- (blue triangles) and Z- (red squares) conformations of oxadiazolecarboxamide-like molecules (a) and the Z-configuration of carbonylamino-hydroxypyrimidinone-like molecules (b). The halogenated phenyl ring conformation RAL geometry in PFV complex is shown in (c and d respectively). The RAL crystal structure parameters are indicated by asterisks. The alternative configurations of the carbonylamino-hydroxypyrimidinone derivatives are demonstrated by structure of RAL precursor molecules, GACMUT, MEADAP and POPYOJ, and RAL inhibitor (d-g).

The oxadiazolecarboxamide-like pharmacophore is observed in the metal complexes as two isomers and demonstrates a strong selectivity to the metal type: the $\mathrm{Z}$ isomer binds $\mathrm{K}$ and $\mathrm{Mg}$ while the $\mathrm{E}$ isomer binds mainly $\mathrm{Mn}$. The higher probability of $\mathrm{Mg}^{2+}$ cation coordination by the Z-isomer of both pharmacophores indicates that the presence of two $\mathrm{Mg}^{2+}$ cations at the integrase binding site may be a decisive factor for stabilisation of the $\mathrm{Z} / \mathrm{Z}$ configuration of RAL which is observed in the PFV intasome complex [2,3].

Therapeutically used RAL is in deprotonated state neutralised by K cation. Such drug formula corresponds to the optimal condition allowing efficient cations replacement in cells. The significantly higher affinity of both parmacophores to $\mathrm{Mg}$ relatively to $\mathrm{K}$ permits a positive competition between these cations, resulting in the change of RAL composition from a pharmaceutically acceptable potassium (K) salt to a biologically relevant $\mathrm{Mg}$ complex. 

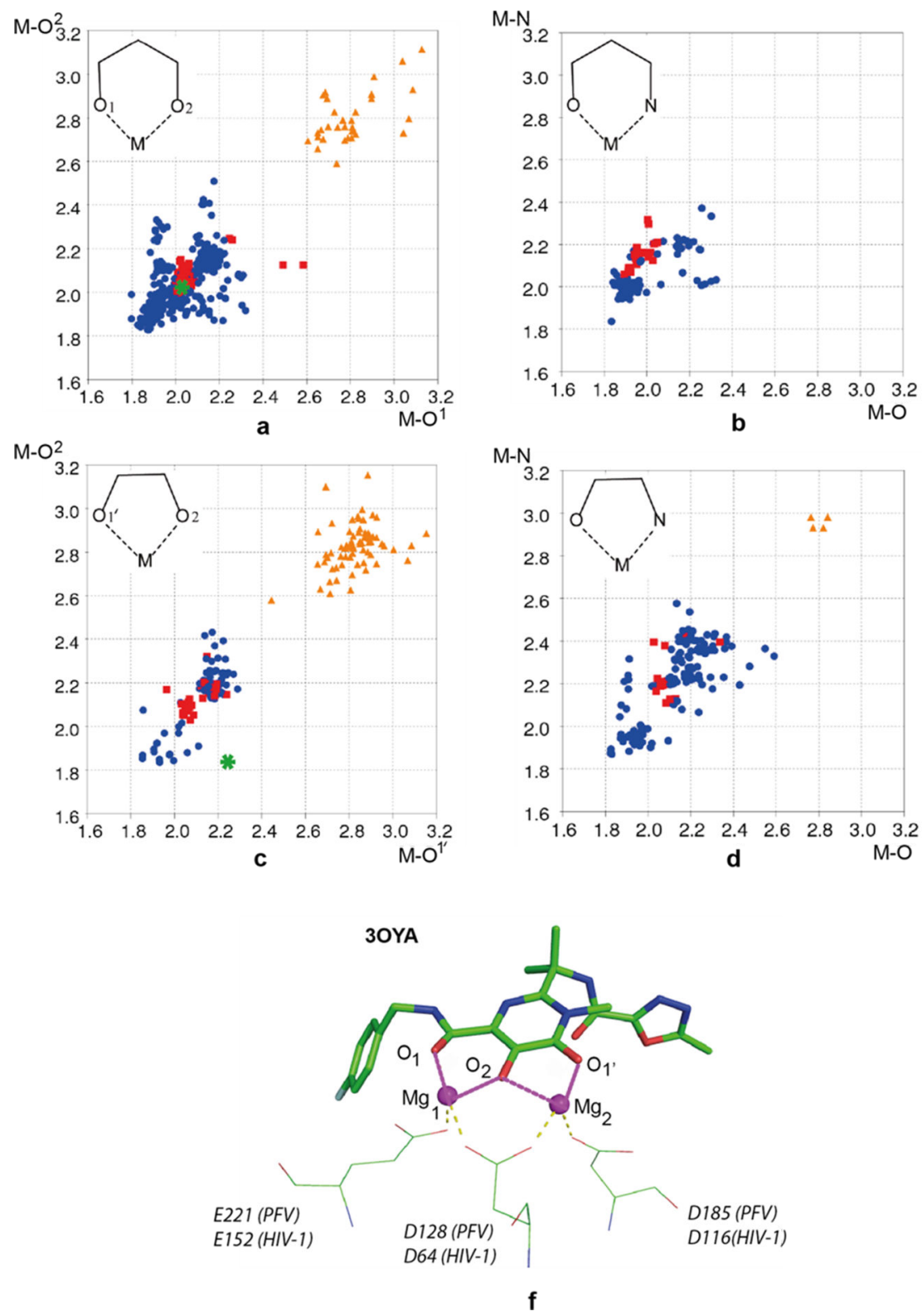

Figure 10. Probing of ligand interactions with $\mathrm{Mg}, \mathrm{Mn}$ and $\mathrm{K}$ by CSD fragment-based search for the metal-ligand complexes (Chart 2, and scatterplots (a-d). Metal complexes are indicated by bull symbols: red squares (Mg), blue circles $(\mathrm{Mn})$ and orange triangles $(\mathrm{K})$. The RAL crystal structure is shown ( $\mathrm{f}$ ) and the RAL parameters are indicated by asterisks in (a and c). 


\subsection{Raltegravir recognition by the HIV-1 targets}

The published docking studies report located within the active site of either unbound IN or IN $\bullet$ vDNA complex. Distinct poses of RAL representing different RAL configuration and modes of $\mathrm{Mg}^{2+}$ cations chelation were observed [74,82-84].

Our docking calculations of RAL onto each model evidenced that (i) the large binding pocket delimited by the active site and the extended catalytic site loop in the unbound IN can accommodate RAL in distinct configurational/conformational states showing a lack of interaction specificity between inhibitor and target; (ii) the well defined cavity formed by the active site, vDNA and shortened catalytic site loop provides a more optimised RAL binding site where the inhibitor is stabilised by coordination bonds with $\mathrm{Mg}^{2+}$ cations in the $\mathrm{Z} / \mathrm{Z}$-configuration (Figure 11).

Additional stabilisation of RAL is provided by non-covalent interactions with the environing residues of IN and the viral DNA bases. Based on our computing data we suggested earlier the stabilizing role of the vDNA in the inhibitors recognition by IN•vDNA preintegration complex [51]. It was experimentally evidenced that RAL potently binds only when IN is in a binary complex with vDNA [85], possibly binding to a transient intermediate along the integration pathway [86]. Terminal bases of the viral DNA play a role in both catalytic efficiency $[87,88]$ and inhibitor binding [89-91].

It was reported recently that unprocessed viral DNA could be the primary target of RAL [92]. This study is based on the PFV DNA and several oligonucleotides mimicking the HIV-1 DNA probed by experimental and computing techniques.

To explore the role of the HIV-1 viral DNA in RAL recognition we docked RAL onto the non-cleaved and cleaved DNA (the terminal GT nucleotides were removed) [79]. We found that RAL docked onto the non-cleaved vDNA is positioned in the minor groove of the substrate. No stabilising interactions between the partners, RAL and vDNA, were observed. In contrast, in the processed (cleaved) vDNA the $\mathrm{Z} / \mathrm{Z}$ isomer of RAL takes the place of the remote GT based and is stabilised by strong and specific H-bonds with the unpaired cytosine. These H-bonds characterize the high affinity and specific recognition between RAL and the unpaired cytosine similarly to those observed in the DNA bases pair G-C.

Based on the docking results we suggested that the inhibition process may include as a first step the RAL recognition by the processed viral DNA bound to a transient intermediate IN state. RAL coupled to vDNA shows an outside orientation of all oxygen atoms, excellent putative chelating agents of $\mathrm{Mg}^{2+}$ cations, which could facilitate the insertion of RAL into the active site. The conformational flexibility of RAL further allows the accommodation/adaptation of the inhibitor in a relatively large binding pocket of IN $\bullet$ vDNA pre-integration complex thus producing various RAL docked conformation. We believe that such variety of RAL conformations contributing to the alternative enzyme residue recognition may impact the selection of the clinically observed alternative resistance pathways to the drug [29] and references herein. 


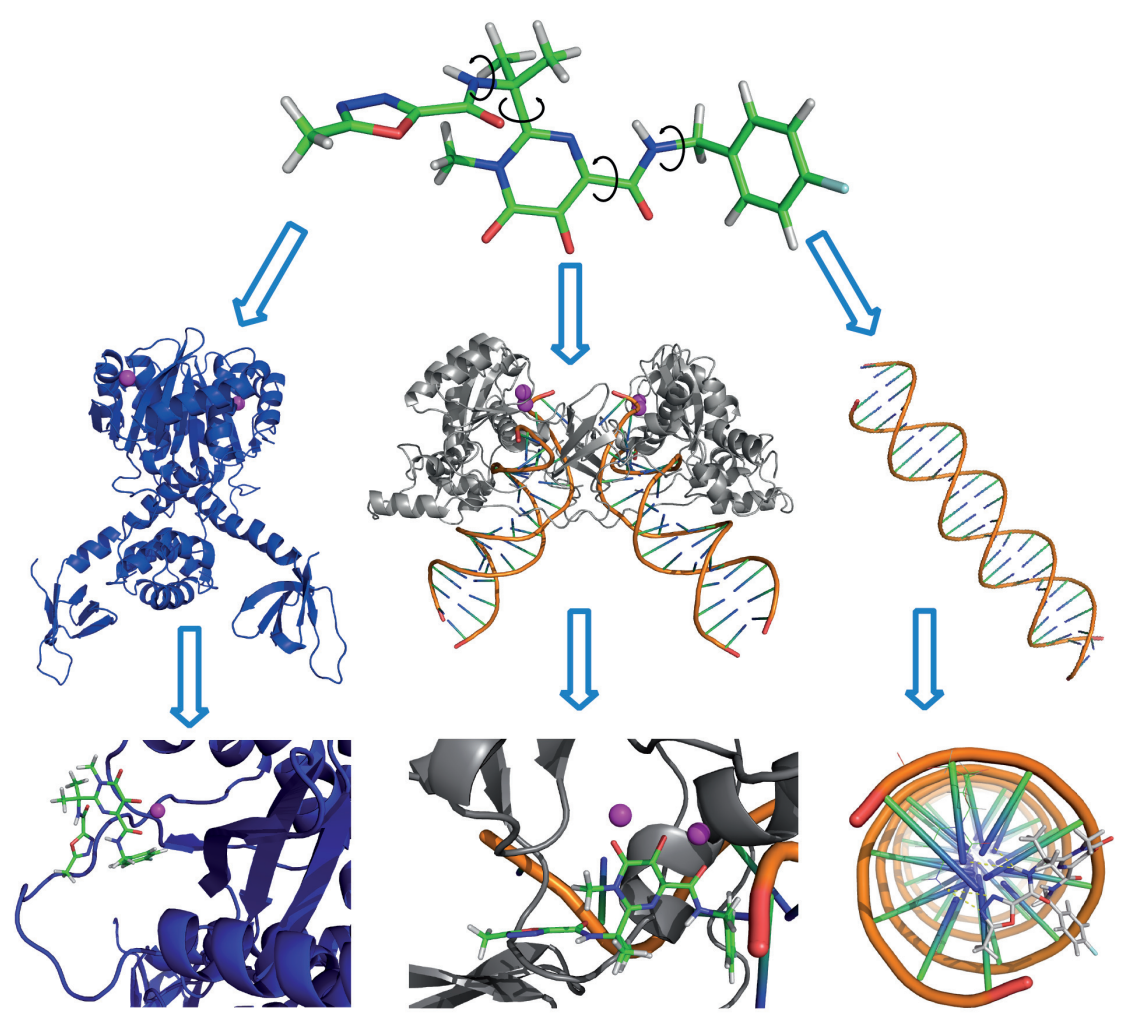

Figure 11. RAL docking onto the active site of unbound IN, IN•vDNA complex and viral DNA. Proteins and DNA are shown as cartoons; inhibitors as sticks and $\mathrm{Mg} 2+$ cations as balls.

\section{Conclusions and perspectives}

The HIV-1 Integrase is an essential retroviral enzyme that covalently binds both ends of linear viral DNA and inserts them into a cellular chromosome. The functions of this enzyme are based on the existence of specific attractive interactions between partner molecules or cofactors - IN, viral DNA and $\mathrm{Mg}^{2+}$ cations. Structure-based drug development seeks to identify and use such interactions to design and optimize the competitive and specific modulator of such functional interactions. Drug design and optimisation process require knowledge about interaction geometries and binding affinity contributing to molecular recognition that can be gleaned from crystallographic and modeling data. 
We have resumed the available structural information related to the retroviral integrase. We used this data to generate biologically relevant HIV-1 targets - the unbound IN, the viral DNA (vDNA) and the IN $\bullet$ vDNA complex - which represent with a certain level of reliability, two different enzymatic states of the HIV-1 over the retroviral integration process.

We have characterised the RAL binding, a very flexible molecule displaying the E/Z isomerism, to the active site of its HIV-1 targets which mimic the integrase states before and after the 3'-processing. The docked conformations represent a spectrum of possible conformational/configurational states. The best docking scores and poses confirm that the generated model representing the IN $\bullet$ vDNA complex is the biologically relevant target of RAL, the strand transfer inhibitor. This finding is consistent with well-documented and commonly accepted inhibition mechanism of RAL, based on integral biological, biochemical and structural data.

RAL docking onto the IN $\bullet$ vDNA complex systematically generated the RAL chelated to $\mathrm{Mg}^{2+}$ cations at the active site by the pharmacophore oxygen atoms. The identification of IN residues specifically interacting with RAL is likely a very difficult task and the exact modes of binding of this inhibitor remain a matter of debate. Most probably the flexible nature of RAL results in different conformations and the mode of binding may differ in terms of the interacting residues of the target, which trigger the alternative resistance phenomenon.

The identified RAL binding to the processed viral DNA shed light on a putative, even plausible, step of the RAL inhibition mechanism.

We have implemented dynamic properties to the HIV-1 targets characterisation, particularly, the internal protein collective motions and the global conformational transition. Such transitions play an essential role in the function of many proteins, but experiments do not provide the atomic details on the path followed in going from one end structure to the other. For the dimeric IN, the transition pathway between the unbound and bound to vDNA is not known, which limits information of the cooperative mechanism in this typical allosteric system, where both tertiary and quaternary changes are involved. Description of the IN intermediate conformations open a way to localise the allosteric pockets, which in turn can be selected as the putative binding sites for small molecules in a virtual screening protocol.

Novel drugs, targeted the HIV-1 Integrase, outcome mainly due to the rapid emergence of RAL analogues (for example, GS-9137 or elvitegravir, MK-2048 and S/GSK 1349572, currently under clinical trials [93]). The clinical trials of several RAL analogues (BMS-707035, GSK-364735) were suspended. All these molecules specifically suppress the IN ST reaction. We conceive that the future HIV-1 integrase drug development will be mainly oriented to design of inhibitors with a mechanism of action that differs from that of RAL and its analogues. Distinct conceptions are potentially conceivable: (i) Design of the allosteric inhibitors, able to recognize specifically the binding sites that differ from the IN active site. Inhibitor V-165, belonging to such type inhibitors, prevents IN binding with the viral DNA such blocking 3'-processing reaction [94]. (ii) Design of the protein-protein inhibitors (PPIs) acting on interaction interface between either viral components (the IN monomers upon multimerization process or sub-units of the IN $\bullet$ vDNA complex) $[95,96]$, or between viral 
and cellular proteins (IN/LEDGF) $[97,98]$. These alternative strategies represent rational and prospective directions in the HIV-1 integrase drug developement.

\section{Acknowledgement}

The authors thank Dr. E. Laine for valuable discussions and for editorial assistance, I. Chauvot de Beauchêne and S. Abdel-Azeim for providing of illustrative materials. This work is funded by the Centre National de la Recherche Scientifique (CNRS), Ecole Normale Supérieure (ENS) de Cachan and SIDACTION.

\section{Author details}

Rohit Arora and Luba Tchertanov

BiMoDyM, LBPA, CNRS -ENS de Cachan, LabEx LERMIT, CEDEX Cachan, France

\section{References}

[1] Berman HM, Westbrook J, Feng Z, Gilliland G, Bhat TN, Weissig H, et al. The Protein Data Bank. Nucleic Acids Research 2000 Jan 1;28(1):235-42.

[2] Hare S, Gupta SS, Valkov E, Engelman A, Cherepanov P. Retroviral intasome assembly and inhibition of DNA strand transfer. Nature 2010 Mar 11;464(7286):232-6.

[3] Hare S, Vos AM, Clayton RF, Thuring JW, Cummings MD, Cherepanov P. Molecular mechanisms of retroviral integrase inhibition and the evolution of viral resistance. Proceedings of the National Academy of Sciences of the United States of America 2010 Nov 16;107(46):20057-62.

[4] Krovat EM, Steindl T, Langer T. Recent Advances in Docking and Scoring. Current Computer-Aided Drug Design 2005 Jan;1(1):93-102.

[5] Brown PO. Integration of Retroviral DNA. Current Topics in Microbiology and Immunology 1990;157:19-48.

[6] Weiss RA. Gulliver's travels in HIV land. Nature 2001 Apr 19;410(6831):963-7.

[7] Chiu TK, Davies DR. Structure and function of HIV-1 integrase. Current Topics in Medicinal Chemistry 2004;4(9):965-77.

[8] Hayouka Z, Rosenbluh J, Levin A, Loya S, Lebendiker M, Veprintsev D, et al. Inhibiting HIV-1 integrase by shifting its oligomerization equilibrium. Proceedings of the 
National Academy of Sciences of the United States of America 2007 May 15;104(20): 8316-21.

[9] Guiot E, Carayon K, Delelis O, Simon F, Tauc P, Zubin E, et al. Relationship between the oligomeric status of HIV-1 integrase on DNA and enzymatic activity. Journal of Biological Chemistry 2006 Aug 11;281(32):22707-19.

[10] Faure A, Calmels C, Desjobert C, Castroviejo M, Caumont-Sarcos A, Tarrago-Litvak L, et al. HIV-1 integrase crosslinked oligomers are active in vitro. Nucleic Acids Research 2005;33(3):977-86.

[11] Wang Y, Klock H, Yin H, Wolff K, Bieza K, Niswonger K, et al. Homogeneous highthroughput screening assays for HIV-1 integrase 3 '-processing and strand transfer activities. Journal of Biomolecular Screening 2005 Aug;10(5):456-62.

[12] Li M, Mizuuchi M, Burke TR, Craigie R. Retroviral DNA integration: reaction pathway and critical intermediates. Embo Journal 2006 Mar 22;25(6):1295-304.

[13] Asante-Appiah E, Skalka AM. Molecular mechanisms in retrovirus DNA integration. Antiviral Research 1997 Dec;36(3):139-56.

[14] Cai ML, Huang Y, Caffrey M, Zheng RL, Craigie R, Clore GM, et al. Solution structure of the His12 -> Cys mutant of the N-terminal zinc binding domain of HIV-1 integrase complexed to cadmium. Protein Science 1998 Dec;7(12):2669-74.

[15] Cai ML, Zheng RL, Caffrey M, Craigie R, Clore GM, Gronenborn AM. Solution structure of the N-terminal zinc binding domain of HIV-1 integrase. Nature Structural Biology 1997 Jul;4(7):567-77.

[16] Eijkelenboom APAM, vandenEnt FMI, Vos A, Doreleijers JF, Hard K, Tullius TD, et al. The solution structure of the amino-terminal HHCC domain of HIV-2 integrase: a three-helix bundle stabilized by zinc. Current Biology 1997 Oct 1;7(10):739-46.

[17] Eijkelenboom APAM, Sprangers R, Hard K, Lutzke RAP, Plasterk RHA, Boelens R, et al. Refined solution structure of the C-terminal DNA-binding domain of human immunovirus-1 integrase. Proteins-Structure Function and Genetics 1999 Sep 1;36(4): 556-64.

[18] Lodi PJ, Ernst JA, Kuszewski J, Hickman AB, Engelman A, Craigie R, et al. Solution structure of the DNA binding domain of HIV-1 integrase. Biochemistry 1995 Aug 8;34(31):9826-33.

[19] Dyda F, Hickman AB, Jenkins TM, Engelman A, Craigie R, Davies DR. Crystal-Structure of the Catalytic Domain of HIV-1 Integrase - Similarity to Other Polynucleotidyl Transferases. Science 1994 Dec 23;266(5193):1981-6.

[20] Bujacz G, Alexandratos J, ZhouLiu Q, ClementMella C, Wlodawer A. The catalytic domain of human immunodeficiency virus integrase: Ordered active site in the F185H mutant. FEBS Letters 1996 Dec 2;398(2-3):175-8. 
[21] Bujacz G, Alexandratos J, Wlodawer A. Binding of different divalent cations to the active site of avian sarcoma virus integrase and their effects on enzymatic activity. Journal of Biological Chemistry 1997 Jul 18;272(29):18161-8.

[22] Maignan S, Guilloteau JP, Zhou-Liu Q, Clement-Mella C, Mikol V. Crystal structures of the catalytic domain of HIV-1 integrase free and complexed with its metal cofactor: High level of similarity of the active site with other viral integrases. Journal of Molecular Biology 1998 Sep 18;282(2):359-68.

[23] Molteni V, Greenwald J, Rhodes D, Hwang Y, Kwiatkowski W, Bushman FD, et al. Identification of a small-molecule binding site at the dimer interface of the HIV integrase catalytic domain. Acta Crystallographica Section D-Biological Crystallography 2001 Apr;57:536-44.

[24] Goldgur Y, Dyda F, Hickman AB, Jenkins TM, Craigie R, Davies DR. Three new structures of the core domain of HIV-1 integrase: An active site that binds magnesium. ProcNatlAcadSci USA 1998 Aug 4;95(16):9150-4.

[25] Goldgur Y, Craigie R, Cohen GH, Fujiwara T, Yoshinaga T, Fujishita T, et al. Structure of the HIV-1 integrase catalytic domain complexed with an inhibitor: A platform for antiviral drug design. Proceedings of the National Academy of Sciences of the United States of America 1999 Nov 9;96(23):13040-3.

[26] Greenwald J, Le V, Butler SL, Bushman FD, Choe S. The mobility of an HIV-1 integrase active site loop is correlated with catalytic activity. Biochemistry 1999 Jul 13;38(28):8892-8.

[27] Chen AP, Weber IT, Harrison RW, Leis J. Identification of amino acids in HIV-1 and avian sarcoma virus integrase subsites required for specific recognition of the long terminal repeat ends. Journal of Biological Chemistry 2006 Feb 17;281(7):4173-82.

[28] Mouscadet JF, Tchertanov L. Raltegravir: molecular basis of its mechanism of action. Eur J Med Res 2009 Nov 24;14 Suppl 3:5-16.

[29] Mouscadet JF, Delelis O, Marcelin AG, Tchertanov L. Resistance to HIV-1 integrase inhibitors: A structural perspective. Drug Resist Updat 2010 Aug;13(4-5):139-50.

[30] Lovell S, Goryshin IY, Reznikoff WR, Rayment I. Two-metal active site binding of a Tn5 transposase synaptic complex. Nature Structural Biology 2002 Apr;9(4):278-81.

[31] Karki R, Tang Y, Nicklaus MC. Model of the HIV-1 integrase-viral DNA complex - A template for structure-based design of HIV in inhibitors. Abstracts of Papers of the American Chemical Society 2002 Aug 18;224:U9-U10.

[32] Karki RG, Tang Y, Burke TR, Nicklaus MC. Model of full-length HIV-1 integrase complexed with viral DNA as template for anti-HIV drug design. Journal of Computer-Aided Molecular Design 2004 Dec;18(12):739-60. 
[33] Wang LD, Liu CL, Chen WZ, Wang CX. Constructing HIV-1 integrase tetramer and exploring influences of metal ions on forming integrase-DNA complex. Biochemical and Biophysical Research Communications 2005 Nov 11;337(1):313-9.

[34] Chen ZG, Yan YW, Munshi S, Li Y, Zugay-Murphy J, Xu B, et al. X-ray structure of simian immunodeficiency virus integrase containing the core and C-terminal domain (residues 50-293) - An initial glance of the viral DNA binding platform. Journal of Molecular Biology 2000 Feb 18;296(2):521-33.

[35] Wang JY, Ling H, Yang W, Craigie R. Structure of a two-domain fragment of HIV-1 integrase: implications for domain organization in the intact protein. Embo Journal 2001 Dec 17;20(24):7333-43.

[36] Ellison V, Gerton J, Vincent KA, Brown PO. An Essential Interaction Between Distinct Domains of Hiv-1 Integrase Mediates Assembly of the Active Multimer. Journal of Biological Chemistry 1995 Feb 17;270(7):3320-6.

[37] Faure A, Calmels C, Desjobert C, Castroviejo M, Caumont-Sarcos A, Tarrago-Litvak $\mathrm{L}$, et al. HIV-1 integrase crosslinked oligomers are active in vitro. Nucleic Acids Research 2005;33(3):977-86.

[38] Guiot E, Carayon K, Delelis O, Simon F, Tauc P, Zubin E, et al. Relationship between the oligomeric status of HIV-1 integrase on DNA and enzymatic activity. Journal of Biological Chemistry 2006 Aug 11;281(32):22707-19.

[39] De Luca L, Pedretti A, Vistoli G, Barreca ML, Villa L, Monforte P, et al. Analysis of the full-length integrase - DNA complex by a modified approach for DNA docking. Biochemical and Biophysical Research Communications 2003 Oct 31;310(4):1083-8.

[40] Esposito D, Craigie R. Sequence specificity of viral end DNA binding by HIV-1 integrase reveals critical regions for protein-DNA interaction. EMBO Journal 1998 Oct 1;17(19):5832-43.

[41] Fenollar-Ferrer C, Carnevale V, Raugei S, Carloni P. HIV-1 integrase-DNA interactions investigated by molecular modelling. Computational and Mathematical Methods in Medicine 2008;9(3-4):231-43.

[42] Wielens J, Crosby IT, Chalmers DK. A three-dimensional model of the human immunodeficiency virus type 1 integration complex. Journal of Computer-Aided Molecular Design 2005 May;19(5):301-17.

[43] Michel F, Crucifix C, Granger F, Eiler S, Mouscadet JF, Korolev S, et al. Structural basis for HIV-1 DNA integration in the human genome, role of the LEDGF/P75 cofactor. EMBO J 2009 Apr 8;28(7):980-91.

[44] Gao K, Butler SL, Bushman F. Human immunodeficiency virus type 1 integrase: arrangement of protein domains in active cDNA complexes. Embo Journal $2001 \mathrm{Jul}$ 2;20(13):3565-76. 
[45] Davies DR, Goryshin IY, Reznikoff WS, Rayment I. Three-dimensional structure of the Tn5 synaptic complex transposition intermediate. Science 2000 Jul 7;289(5476): 77-85.

[46] Podtelezhnikov AA, Gao K, Bushman FD, McCammon JA. Modeling HIV-1 integrase complexes based on their hydrodynamic properties. Biopolymers 2003 Jan;68(1): $110-20$.

[47] Ren G, Gao K, Bushman FD, Yeager M. Single-particle image reconstruction of a tetramer of HIV integrase bound to DNA. Journal of Molecular Biology 2007 Feb 9;366(1):286-94.

[48] Mouscadet JF, Arora R, Andre J, Lambry JC, Delelis O, Malet I, et al. HIV-1 IN alternative molecular recognition of DNA induced by raltegravir resistance mutations. Journal of Molecular Recognition 2009 Nov;22(6):480-94.

[49] Tama F, Gadea FX, Marques O, Sanejouand YH. Building-block approach for determining low-frequency normal modes of macromolecules. Proteins 2000 Oct 1;41(1): $1-7$.

[50] Tama F, Sanejouand YH. Conformational change of proteins arising from normal mode calculations. Protein Eng 2001 Jan;14(1):1-6.

[51] Ni X, Abdel-Azeim S, Laine E, Arora R, Osemwota O, Marcelin A-G, et al. In silico and in vitro Comparison of HIV-1 Subtypes B and CRF02_AG Integrases Susceptibility to Integrase Strand Transfer Inhibitors. Advances in Vilology 2012;2012:548657.

[52] Yin ZQ, Craigie R. Modeling the HIV-1 Intasome: A Prototype View of the Target of Integrase Inhibitors. Viruses-Basel 2010 Dec;2(12):2777-81.

[53] Karplus M, Kuriyan J. Molecular dynamics and protein function. Proc Natl Acad Sci U S A 2005 May 10;102(19):6679-85.

[54] Karplus M, Gao YQ, Ma J, van d, V, Yang W. Protein structural transitions and their functional role. Philos Transact A Math Phys Eng Sci 2005 Feb 15;363(1827):331-55.

[55] Gerstein M, Lesk AM, Chothia C. Structural mechanisms for domain movements in proteins. Biochemistry 1994 Jun 7;33(22):6739-49.

[56] Schlitter J, Engels M, Kruger P. Targeted molecular dynamics: a new approach for searching pathways of conformational transitions. J Mol Graph 1994 Jun;12(2):84-9.

[57] Bagley RJ, Farmer JD, Kauffman SA, Packard NH, Perelson AS, Stadnyk IM. Modeling adaptive biological systems. Biosystems 1989;23(2-3):113-37.

[58] Cotelle P. Patented HIV-1 integrase inhibitors (1998-2005). Recent Pat Antiinfect Drug Discov 2006 Jan;1(1):1-15.

[59] Pommier Y, Johnson AA, Marchand C. Integrase inhibitors to treat HIV/AIDS. Nature Reviews Drug Discovery 2005 Mar;4(3):236-48. 
[60] Semenova EA, Marchand C, Pommier Y. HIV-1 integrase inhibitors: Update and Perspectives. Adv Pharmacol 2008;56:199-228.

[61] Marchand C, Maddali K, Metifiot M, Pommier Y. HIV-1 IN Inhibitors: 2010 Update and Perspectives. Current Topics in Medicinal Chemistry 2009 Aug;9(11):1016-37.

[62] Hazuda DJ, Felock P, Witmer M, Wolfe A, Stillmock K, Grobler JA, et al. Inhibitors of strand transfer that prevent integration and inhibit HIV-1 replication in cells. Science 2000 Jan 28;287(5453):646-50.

[63] Markowitz M, Morales-Ramirez JO, Nguyen BY, Kovacs CM, Steigbigel RT, Cooper DA, et al. Antiretroviral activity, pharmacokinetics, and tolerability of MK-0518, a novel inhibitor of HIV-1 integrase, dosed as monotherapy for 10 days in treatmentnaive HIV-1-infected individuals. J Acquir Immune DeficSyndr. 2006 Dec 15;43(5): 509-15.

[64] Grobler JA, Stillmock K, Hu B, Witmer M, Felock P, Espeseth AS, et al. Diketo acid inhibitor mechanism and HIV-1 integrase: implications for metal binding in the active site of phosphotransferase enzymes.ProcNatlAcadSci USA. 2002 May 14;99(10): 6661-6.

[65] Garvey EP, Schwartz B, Gartland MJ, Lang S, Halsey W, Sathe G, et al. Potent inhibitors of HIV-1 integrase display a two-step, slow-binding inhibition mechanism which is absent in a drug-resistant T66I/M154I mutant.Biochemistry. 2009 Feb 24;48(7):1644-53.

[66] Copeland RA, Pompliano DL, Meek TD. Drug-target residence time and its implications for lead optimization.Nat Rev Drug Discov. 2006 Sep;5(9):730-9.

[67] Dicker IB, Terry B, Lin Z, Li Z, Bollini S, Samanta HK, et al. Biochemical analysis of HIV-1 integrase variants resistant to strand transfer inhibitors. J Biol Chem. 2008 Aug 29;283(35):23599-609.

[68] Hightower KE, Wang R, Deanda F, Johns BA, Weaver K, Shen Y, et al. Dolutegravir (S/GSK1349572) exhibits significantly slower dissociation than raltegravir and elvitegravir from wild-type and integrase inhibitor-resistant HIV-1 integrase-DNA complexes.Antimicrob Agents Chemother. 2011 Oct;55(10):4552-9.

[69] Cooper DA, Steigbigel RT, Gatell JM, Rockstroh JK, Katlama C, Yeni P, et al. Subgroup and resistance analyses of raltegravir for resistant HIV-1 infection. New England Journal of Medicine 2008 Jul 24;359(4):355-65.

[70] Steigbigel RT, Cooper DA, Kumar PN, Eron JE, Schechter M, Markowitz M, et al. Raltegravir with optimized background therapy for resistant HIV-1 infection. New England Journal of Medicine 2008 Jul 24;359(4):339-54.

[71] Sichtig N, Sierra S, Kaiser R, Daumer M, Reuter S, Schulter E, et al. Evolution of raltegravir resistance during therapy. Journal of Antimicrobial Chemotherapy 2009 Jul; 64(1):25-32. 
[72] Grobler JA, Stillmock KA, Miller MD, Hazuda DJ. Mechanism by which the HIV integrase active-site mutation $\mathrm{N} 155 \mathrm{H}$ confers resistance to raltegravir. Antiviral Therapy 2008;13(4):A41.

[73] Delelis O, Malet I, Na L, Tchertanov L, Calvez V, Marcelin AG, et al. The G140S mutation in HIV integrases from raltegravir-resistant patients rescues catalytic defect due to the resistance Q148H mutation. Nucleic Acids Research 2009 Mar;37(4): 1193-201.

[74] Perryman AL, Forli S, Morris GM, Burt C, Cheng YH, Palmer MJ, et al. A Dynamic Model of HIV Integrase Inhibition and Drug Resistance. Journal of Molecular Biology 2010 Mar 26;397(2):600-15.

[75] Delelis O, Thierry S, Subra F, Simon F, Malet I, Alloui C, et al. Impact of Y143 HIV-1 Integrase Mutations on Resistance to Raltegravir In Vitro and In Vivo. Antimicrobial Agents and Chemotherapy 2010 Jan;54(1):491-501.

[76] Kawasuji T, Fuji M, Yoshinaga T, Sato A, Fujiwara T, Kiyama R. A platform for designing HIV integrase inhibitors. Part 2: A two-metal binding model as a potential mechanism of HIV integrase inhibitors. Bioorganic \& Medicinal Chemistry 2006 Dec 15;14(24):8420-9.

[77] Allen FH. The Cambridge Structural Database: a quarter of a million crystal structures and rising. Acta Crystallogr B 2002 Jun;58(Pt 3 Pt 1):380-8.

[78] Tchertanov L, Mouscadet JF. Target recognition by catechols and beta-ketoenols: Potential contribution of hydrogen bonding and $\mathrm{Mn} / \mathrm{Mg}$ chelation to HIV-1 integrase inhibition. Journal of Medicinal Chemistry 2007 Mar 22;50(6):1133-45.

[79] Arora R, Chauvot de Beauchêne I, Abdel-Azeim S, Polanski J, Laine E, Tchertanov L. Raltegravir flexibility and its impact on recognition by the HIV-1 Integrase targets. Journal of Molecular Recognition 2012. Submitted

[80] Arora R, Tchertanov L. Structural determinants of Raltegravir specific recognition by the HIV-1 Integrase. 2012. Les actes: 57-60. http://jobim2012.inria.fr/ jobim_actes_2012_online.pdf

[81] Schiavoni MM, Mack HG, Ulic SE, Della Vedova CO. Tautomers and conformers of malonamide, NH2-C(O)-CH2-C(O)-NH2: vibrational analysis, NMR spectra and ab initio calculations. Spectrochim Acta A Mol Biomol Spectrosc 2000 Jul;56A(8): 1533-41.

[82] Barreca ML, Iraci N, De Luca L, Chimirri A. Induced-Fit Docking Approach Provides Insight into the Binding Mode and Mechanism of Action of HIV-1 Integrase Inhibitors. Chemmedchem 2009 Sep;4(9):1446-56.

[83] Loizidou EZ, Zeinalipour-Yazdi CD, Christofides T, Kostrikis LG. Analysis of binding parameters of HIV-1 integrase inhibitors: Correlates of drug inhibition and resistance. Bioorganic \& Medicinal Chemistry 2009 Jul 1;17(13):4806-18. 
[84] Serrao E, Odde S, Ramkumar K, Neamati N. Raltegravir, elvitegravir, and metoogravir: the birth of "me-too" HIV-1 integrase inhibitors. Retrovirology 2009;6:25.

[85] Espeseth AS, Felock P, Wolfe A, Witmer M, Grobler, J, Anthony N., et al.HIV-1 integrase inhibitors that compete with the target DNA substrate define a unique strand transfer conformation for integrase. Proc. Natl. Acad. Sci. U.S.A 2000; 97:11244-49.

[86] Pandey KK., Bera S., Zahm J., Vora A, Stillmock K., Hazuda D, et al. Inhibition of human immunodeficiency virus type 1 concerted integration by strand transfer inhibitors which recognize a transient structural intermediate. J. Virol. 2007; 81: 12189-99.

[87] Sherman PA, Dickson ML. and Fyfe JA. Human immunodeficiency virus type 1 integration protein: DNA sequence requirements for cleaving and joining reactions. J. Virol. 1992; 66: 3593-601.

[88] Johnson AA, Santos W, Pais GCG, Marchand C, Amin, R., Burker, T. R., Jr., Verdine, G., and Pommier, Y. Integration requires a specific interaction of the donor DNA terminal $5^{\prime}$-cytosine with glutamine 148 of the HIV-1 integrase flexible loop. J. Biol. Chem. 2006; 281,:461-7.

[89] Johnson AA, Marchand C, Patil SS, Costi R, DiSanto R, Burke, R. R. Jr. et al. Probing HIV-1 integrase inhibitor binding sites with position-specific integrase-DNA crosslinking assays. Mol. Pharmacol. 2007; 71: 893-901.

[90] Dicker IB, Samanta HK, Li A, Hong Y, Tian Y, Banville J et al. Changes to the HIV long terminal repeat and to HIV integrase differentially impact HIV integrase assembly, activity, and the binding of strand transfer inhibitors. J. Biol. Chem. 2008; 282: 31186-96.

[91] Langley D, Samanta HK, Lin Z, Walker MA, Krystal M, and Dicker IB. The Terminal (Catalytic) Adenosine of the HIV LTR Controls the Kinetics of Binding and Dissociation of HIV Integrase Strand Transfer Inhibitors. Biochemistry 2008; 47: 13481-8.

[92] Ammar FF, Abdel-Azeim S, Zargarian L, Hobaika Z, Maroun RG, Fermandjian S Unprocessed Viral DNA Could Be the Primary Target of the HIV-1 Integrase Inhibitor Raltegravir. PLoS One.oS One. 2012;7(7):e40223.

[93] Korolev S, Agapkina Yu, Gottikh M. Clinical Use of Inhibitors of HIV-1 Integration: Problems and Prospects. Acta Naturae 2011;3;3:12-28.

[94] Pannecouque C, Pluymers W, Van Maele B, Tetz V, Cherepanov P, De Clercq E, et al. New class of HIV integrase inhibitors that block viral replication in cell culture. Curr Biol. 2002 Jul 23;12(14):1169-77.

[95] Mazumder A, Wang S, Neamati N, Nicklaus M, Sunder S, Chen J, et al. Antiretroviral agents as inhibitors of both human immunodeficiency virus type 1 integrase and protease.J Med Chem. 1996 Jun 21;39(13):2472-81. 
[96] Tsiang M, Jones GS, Hung M, Samuel D, Novikov N, Mukund S, et al. Dithiothreitol causes HIV-1 integrase dimer dissociation while agents interacting with the integrase dimer interface promote dimer formation. Biochemistry. 2011 Mar 15;50(10):1567-81.

[97] De Luca L, Ferro S, Gitto R, Barreca ML, Agnello S, Christ F, et al. Small molecules targeting the interaction between HIV-1 integrase and LEDGF/p75 cofactor. Bioorg Med Chem. 2010 Nov 1;18(21):7515-21.

[98] Tsiang M, Jones GS, Niedziela-Majka A, Kan E, Lansdon EB, Huang W, Hung M, et al. New Class of HIV-1 Integrase (IN) Inhibitors with a Dual Mode of Action.Biol Chem. 2012 Jun 15;287(25):21189-203. 
